\title{
Condutividade hidráulica de solos de Pernambuco em resposta à condutividade elétrica e RAS da água de irrigação ${ }^{1}$
}

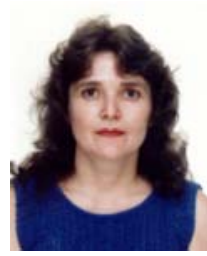

\author{
Maria B. G. dos S. Freire ${ }^{2}$, Hugo A. Ruiz ${ }^{3}$, Mateus R. Ribeiro ${ }^{4}$, Paulo A. Ferreira ${ }^{5}$, \\ Victor H. Alvarez V. ${ }^{6}$ \& Fernando J. Freire ${ }^{7}$
}

\footnotetext{
1 Parte da Tese de Doutorado do primeiro autor, apresentada a Universidade Federal de Viçosa

2 UFRPE/DEPA. R. Dom Manoel de Medeiros s/n, Dois Irmãos, CEP 52171-900, Recife, PE. Fone: (81) 3302-1220. E-mail: mbetaniafreire@uol.com.br (Foto)

3 UFV/DPS. CEP 36571-000, Viçosa, MG. Fone: (31) 3899 1052. E-mail: hruiz@mail.ufv.br

4 UFRPE/DEPA. Fone: (81) 3302 1233. E-mail: rosas@truenet.com.br

5 UFV/DEA. Fone: (31) 3899 1911. E-mail: pafonso@mail.ufv.br

6 UFV/DPS. Fone: (31) 3899 1061. E-mail: vhav@mail.ufv.br

7 UFRPE/DEPA. Fone: (81) 3302 1226. E-mail: fernandojfreire@uol.com.br
}

Protocolo 47 - 15/4/2002 - Aprovado em 20/2/2003

\begin{abstract}
Resumo: Objetivando-se avaliar a condutividade hidráulica em solos irrigados com águas de diferentes condutividades elétricas (CE) e relações de adsorção de sódio (RAS) realizaram-se ensaios em permeâmetros de coluna vertical e carga constante. Os tratamentos corresponderam a nove solos, três CE $\left(175,500\right.$ e $1.500 \mu \mathrm{S} \mathrm{cm}^{-1}$ ) e seis RAS (de 0 a 30 para solos arenosos, de 0 a 25 para solos de textura média e de 0 a 15 para solos de textura argilosa). De início, realizou-se o ajuste da relação $\mathrm{Na}: \mathrm{Ca}$ no complexo de troca catiônico dos solos, utilizando-se soluções na concentração de $50 \mathrm{mmol}_{\mathrm{c}} \mathrm{L}^{-1}$, nos níveis de RAS descritos; depois, determinou-se a condutividade hidráulica em meio saturado $\left(K_{0}\right)$ e se calculou a condutividade hidráulica relativa $\left(\mathrm{K}_{\mathrm{OR}}\right)$, atribuindo-se o valor de $100 \%$ à máxima $\mathrm{K}_{\mathrm{o}}$ média de cada solo. Os valores de $\mathrm{K}_{\mathrm{OR}}$ foram relacionados com a CE e a RAS dos tratamentos impostos, ajustando-se superfícies de resposta. As correlações entre $K_{0}$ e a percentagem de sódio trocável (PST) indicaram relação inversa entre as duas variáveis, na maioria dos solos estudados. O incremento da RAS levou à diminuição da Ков. Não foi possível se fixar um único valor de PST no estabelecimento de um limite para solos sódicos, devendo esta característica ser associada à CE da água de irrigação e a outras propriedades do solo, como textura e mineralogia.
\end{abstract}

Palavras-chave: solo sódico, condutividade elétrica, relação de adsorção de sódio

\section{Hydraulic conductivity of soils from Pernambuco in response to electrical conductivity and SAR of irrigation water}

\begin{abstract}
An experiment was carried out in permeameters provided on vertical soil columns with constant hydraulic head in order to evaluate the hydraulic conductivity of soils with contrasting characteristics, and treated with solutions of different electrical conductivities (EC) and sodium adsorption ratios (SAR). The treatments consisted of nine soils, three EC values $(175,500$ and $1.500 \mu \mathrm{S} \mathrm{cm}^{-1}$ ) and six SAR values of the irrigation water ( 0 to 30 for sandy soils, 0 to 25 for medium textured soils, and $\mathrm{O}$ to 15 for clay textured soils). Initially, an adjustment of the $\mathrm{Na:Ca}$ ratio in the cation exchange complex was performed with solutions at concentration of $50 \mathrm{mmol}_{\mathrm{c}} \mathrm{L}^{-1}$. The saturated hydraulic conductivity of soil (Ko) was measured and the relative hydraulic conductivity (KoR) was determined, considering the maximum average Ko values of each soil as $100 \%$. The Kor values were related to CE and SAR of the treatments, by adjusting the response surfaces. The correlation between $\mathrm{K}_{0}$ and the exchangeable sodium percentage (ESP) showed an inverse relationship between both variables in most of the studied soils. The increment in SAR resulted in the decrease of the Kor. It was not possible to define just one ESP value in order to establish a limit for sodic soils. ESP should be considered together with the EC of the irrigation water, as well as soil properties such as texture and mineralogy.
\end{abstract}

Key words: sodic soil, electrical conductivity, sodium adsorption ratio 


\section{INTRODUÇÃO}

A degradação de solos pela sodificação tem-se tornado um problema cada vez mais freqüente em regiões áridas, onde a reduzida precipitação não é suficiente para promover a lixiviação e retirada dos sais de sódio do meio. A predominância de sódio em relação aos demais cátions, no complexo de troca, pode promover a dispersão e migração dos colóides no perfil do solo, com obstrução de poros e redução da movimentação de ar e água, dificultando o crescimento dos vegetais.

A percentagem de sódio trocável (PST) é a variável que representa a proporção desse cátion em relação a capacidade de troca catiônica, e é usada como critério na classificação de solos afetados por sais. Estudos conduzidos pelo Laboratório de Salinidade dos Estados Unidos, na década de 50, estabeleceram um limite de $15 \%$ para a PST, acima do qual os solos são classificados como sódicos (Richards, 1954). O trabalho de Fireman \& Wadleigh (1951) correlacionou a PST com o pH do solo, partindo do princípio de que existia uma relação direta entre $\mathrm{pH}$ e sódio trocável, objetivando identificar os problemas de sodicidade dos solos a partir da determinação do $\mathrm{pH}$, muito mais simples que a do sódio trocável; entretanto, o comportamento não é o mesmo para a diversidade de solos existentes no mundo.

A classificação americana tem sido utilizada em todo o mundo para definir solos sódicos; porém, ela foi desenvolvida para os solos e as condições específicas do oeste dos Estados Unidos (Fireman \& Wadleigh, 1951; Richards, 1954). Recentemente, têm surgido pesquisas que visam modificar esses limites. A influência da textura foi reconhecida por Greene et al. em 1978, citados por Sumner (1995) que mudaram a PST crítica para $10 \%$ em solos de textura argilosa e $20 \%$ para os de textura arenosa. Na Austrália adotou-se o valor de PST $>6 \%$, no metro superior do perfil, para classificar um solo como sódico, pois esta PST é capaz de modificar o comportamento dos solos australianos, aumentando a dispersão e reduzindo a condutividade hidráulica (Northcote \& Skene, 1972).

A PST de 15\%, estabelecida na Califórnia como o limite acima do qual a estrutura do solo é adversamente afetada (Richards, 1954) foi fixada com base na determinação da condutividade hidráulica em meio saturado, medida com o uso de águas de concentrações de sais (entre 3 e 10 mmol $_{c} \mathrm{~L}^{-1}$ ). O limite da Austrália foi estabelecido da mesma forma; entretanto, com água de menor concentração de eletrólitos $\left(0,7 \mathrm{mmol}_{\mathrm{c}} \mathrm{L}^{-1}\right)$ (Northcote \& Skene, 1972). Assim, no estudo da Califórnia foi preciso uma PST maior para evidenciar o processo de degradação dos solos. Fica demonstrado, então, que a relação entre a PST de um solo e a concentração de sais solúveis da solução do solo ou da água de percolação é de grande importância na determinação de seu comportamento no campo.

Também na Austrália, McIntyre (1979) determinou a PST crítica de 5\%, por detectar que, a partir deste ponto, a condutividade hidráulica em meio saturado tornava-se inferior a $0,1 \mathrm{~cm} \mathrm{~h}^{-1}$, valor considerado por Richards (1954) como limite para solos irrigados. $\mathrm{O}$ autor argumenta que o limite para a Austrália é baixo devido à predominância de solos argilosos, muitos deles com elevados teores de magnésio trocável, superiores aos do cálcio.
É de grande importância o controle criterioso da água usada na irrigação, principalmente quando de baixa condutividade elétrica (CE) e relações de adsorção de sódio (RAS) mais elevada, o que pode favorecer a dispersão dos colóides. A infiltração da água de chuva em solos salino-sódicos, por exemplo, poderá agravar os problemas próprios desses solos, ao lixiviar os sais solúveis e provocar a dispersão, promovendo redução na condutividade hidráulica (McNeal \& Coleman, 1966; Minhas \& Sharma, 1986). Assim, com este trabalho objetivou-se avaliar a condutividade hidráulica de solos de textura e natureza diversas, tratados com soluções de diferentes CE e RAS.

\section{MATERIAL E MÉTODOS}

As amostras de solo utilizadas, coletadas de horizontes selecionados de nove perfis representativos do Estado de Pernambuco (Ribeiro et al., 1999), foram identificadas e caracterizadas física, química e mineralogicamente (Freire, 2001).

Os tratamentos corresponderam a nove solos, três valores de CE e seis valores de RAS da água de irrigação, em três repetições, dispostos em um delineamento em blocos casualizados.

Inicialmente, realizou-se o ajuste da relação $\mathrm{Na}: \mathrm{Ca}$ do complexo de troca catiônico, através de permeâmetros de carga constante montados em colunas de PVC de $5 \mathrm{~cm}$ de diâmetro por $20 \mathrm{~cm}$ de comprimento, fechados na parte inferior com tela forrada com um disco de lã de vidro. O solo foi acondicionado cuidadosamente, homogeneizando-se sua distribuição com bastão de vidro para evitar a formação de camadas de compactação diferente, até uma altura de $6 \mathrm{~cm}$. Na parte superior da coluna foi colocado outro disco de lã de vidro, para evitar distúrbios na superfície quando da passagem das soluções.

As soluções utilizadas para o ajuste da relação $\mathrm{Na}: \mathrm{Ca}$ (soluções saturantes) foram preparadas de forma a se chegar a uma concentração final de $50 \mathrm{mmol}_{\mathrm{c}} \mathrm{L}^{-1}$; para isto, misturaram-se soluções de $\mathrm{NaCl}$ e de $\mathrm{CaCl}_{2}$, de concentração apropriada, que permitiram se conseguir os valores de RAS estabelecidos para cada tratamento: 0 a $30\left(\mathrm{mmol} \mathrm{L}^{-1}\right)^{1 / 2}$ para solos arenosos, 0 a 25 $\left(\mathrm{mmol} \mathrm{L}^{-1}\right)^{1 / 2}$ para solos de textura média e 0 a $15\left(\mathrm{mmol} \mathrm{L}^{-1}\right)^{1 / 2}$ para solos de textura argilosa e muito argilosa (Freire, 2001).

As colunas foram colocadas para saturar dentro de recipientes cilíndricos de plástico, contendo a solução saturante, conforme o tratamento, até uma altura correspondente a dois terços da altura da amostra de solo $(4 \mathrm{~cm})$, para que a saturação ocorresse no sentido ascendente eliminando, ao máximo, o ar do espaço poroso do solo. Permaneceram assim por $48 \mathrm{~h}$, quando foram montados os permeâmetros de coluna vertical e carga constante, conforme Ferreira (1999). A solução saturante foi aplicada até atingir o equilíbrio, quando a condutividade elétrica do efluente correspondesse aproximadamente à mesma da solução aplicada. $\mathrm{O}$ volume aplicado de solução equivaleu a aproximadamente 50 vezes o volume de poros de cada solo na coluna; posteriormente, as colunas de solo foram mantidas em recipientes com as soluções saturantes por mais $24 \mathrm{~h}$.

Após a finalização do ajuste da relação $\mathrm{Na}: \mathrm{Ca}$, os permeâmetros foram remontados para determinar a condutividade hidráulica em meio saturado, com soluções nos mesmos níveis da RAS previamente utilizados, porém a valores de CE diferenciados $\left(175,500\right.$ e $\left.1.500 \mu \mathrm{S} \mathrm{cm}^{-1}\right)$. As soluções foram 
aplicadas às colunas, utilizando-se o sistema do "frasco de Mariotte", para manutenção de carga constante (Ferreira, 1999).

Como as amostras estavam saturadas com uma solução concentrada $\left(50 \mathrm{mmol}_{\mathrm{c}} \mathrm{L}^{-1}\right)$, percolou-se $1 \mathrm{~L}$ de solução correspondente a cada tratamento, cujo volume foi considerado suficiente para assegurar condutividades elétricas iguais entre a solução do solo e a solução de trabalho. Em seguida, iniciouse o procedimento de determinação da condutividade hidráulica em laboratório (Ferreira, 1999). Os volumes percolados no intervalo de tempo foram registrados calculando-se a condutividade hidráulica em meio saturado:

$$
\mathrm{K}_{\mathrm{e}}=\frac{\mathrm{VL}}{\operatorname{At}(1+\mathrm{L})}
$$

em que $\mathrm{K}_{\mathrm{e}}$ é a condutividade hidráulica em meio saturado $\left(\mathrm{cm} \mathrm{s}^{-1}\right)$; V é o volume do efluente coletado na proveta $(\mathrm{mL})$; L é a espessura da amostra de solo (cm); A é a área transversal da coluna de solo $\left(\mathrm{cm}^{2}\right)$; t é o tempo (s); e lé a espessura da lâmina de solução acima da superfície do solo $(\mathrm{cm})$.

$\mathrm{O}$ valor de $\mathrm{K}_{\mathrm{e}}$, determinado para as condições ambientais, foi recalculado para a temperatura de referência de $20^{\circ} \mathrm{C}$. Depois de determinada a temperatura da solução de cada coluna de solo, aplicou-se a fórmula:

$$
\mathrm{K}_{0}=\mathrm{K}_{\mathrm{e}}\left(\frac{\eta_{\mathrm{e}}}{\eta_{20}}\right)
$$

em que $\mathrm{K}_{0}$ é a condutividade hidráulica a temperatura-padrão de $20{ }^{\circ} \mathrm{C}\left(\mathrm{cm} \mathrm{s}^{-1}\right) ; \mathrm{K}_{\mathrm{e}}$ é a condutividade hidráulica experimental $\left(\mathrm{cm} \mathrm{s}^{-1}\right) ; \eta_{\mathrm{e}}$ é a viscosidade dinâmica da água a temperatura ambiente (centipoise); e $\eta_{20}$ é a viscosidade dinâmica da água a $20{ }^{\circ} \mathrm{C}$ (centipoise). A viscosidade foi obtida de tabelas.

As colunas foram desmontadas e as amostras de solo foram secas ao ar, destorroadas e passadas em peneira de $2 \mathrm{~mm}$ para determinação do sódio trocável e da capacidade de troca de cátions, possibilitando calcular a PST de cada amostra de solo (Freire, 2001).

\section{RESULTADOS E DISCUSSÃO}

A condutividade hidráulica em meio saturado das amostras $\left(\mathrm{K}_{0}\right)$, determinada com a utilização das soluções de trabalho, está apresentada na Tabela 1. A não-uniformidade de variâncias não permitiu a comparação dos diferentes solos, porém se observam os maiores valores de $\mathrm{K}_{0}$ no Neossolo Quartzarênico, no Argissolo Vermelho-Amarelo, no Planossolo Háplico e no Argissolo Amarelo. Esses valores mais elevados podem ser atribuídos à textura arenosa, no Neossolo Quartzarênico (94,4\% de areia); à maior relação areia grossa/ areia fina e ao baixo teor de silte, no Planossolo Háplico; ao caráter plíntico, no Argissolo Amarelo; ou à elevada floculação de argilas, nos Argissolos Vermelho-Amarelo e Amarelo (Freire, 2001)

Conforme classificação da condutividade hidráulica em meio saturado sugerido por Ferreira (1999)* a K 0 variou de muito rápida

Tabela 1. Condutividade hidráulica $\left(\mathrm{K}_{0}\right)$ em meio saturado das amostras de solo, considerando-se a condutividade elétrica (CE) e

\begin{tabular}{|c|c|c|c|c|c|c|c|c|c|}
\hline $\begin{array}{l}\text { Nível da } \\
\text { RAS }\end{array}$ & $\begin{array}{c}\text { Neossolo } \\
\text { Quartzarênico }\end{array}$ & $\begin{array}{l}\text { Neossolo } \\
\text { Regolítico }\end{array}$ & $\begin{array}{l}\text { Neossolo } \\
\text { Flúvico }\end{array}$ & $\begin{array}{c}\text { Luvissolo } \\
\text { Crômico }\end{array}$ & $\begin{array}{c}\text { Chernossolo } \\
\text { Argilúvico }\end{array}$ & $\begin{array}{l}\text { Luvissolo } \\
\text { Hipocrômico }\end{array}$ & $\begin{array}{c}\text { Argissolo } \\
\text { Vermelho- } \\
\text { Amarelo }\end{array}$ & $\begin{array}{c}\text { Planossolo } \\
\text { Háplico }\end{array}$ & $\begin{array}{c}\text { Argissolo } \\
\text { Amarelo }\end{array}$ \\
\hline & \multicolumn{9}{|c|}{$\mathrm{K}_{0}-\mathrm{cm} \mathrm{h}^{-1}$} \\
\hline \multicolumn{10}{|c|}{ Condutividade Elétrica $175 \mu \mathrm{S} \mathrm{cm}^{-1}$} \\
\hline 1 & 72,58 & 1,48 & 0,42 & 2,16 & 1,45 & 0,79 & 7,17 & 6,39 & 5,11 \\
\hline 2 & 83,63 & 0,69 & 0,15 & 2,48 & 0,86 & 0,28 & 4,93 & 4,90 & 3,75 \\
\hline 3 & 73,30 & 0,81 & 0,08 & 1,46 & 0,30 & 0,13 & 6,75 & 4,22 & 4,35 \\
\hline 4 & 84,35 & 0,40 & 0,05 & 1,00 & 0,16 & 0,01 & 7,29 & 2,93 & 4,26 \\
\hline 5 & 84,32 & 0,33 & 0,02 & 0,35 & 0,09 & 0,00 & 7,25 & 1,14 & 4,48 \\
\hline 6 & 75,63 & 0,39 & 0,01 & 0,27 & 0,05 & 0,00 & 5,82 & 1,23 & 3,88 \\
\hline \multicolumn{10}{|c|}{ Condutividade Elétrica $500 \mu \mathrm{S} \mathrm{cm}^{-1}$} \\
\hline 1 & 89,43 & 1,43 & 0,64 & 2,24 & 1,85 & 1,33 & 6,11 & 6,23 & 4,65 \\
\hline 2 & 79,57 & 0,86 & 0,33 & 2,66 & 1,34 & 0,90 & 5,42 & 5,44 & 6,06 \\
\hline 3 & 89,76 & 0,78 & 0,12 & 2,69 & 1,07 & 0,35 & 7,29 & 4,58 & 3,69 \\
\hline 4 & 90,54 & 0,53 & 0,09 & 1,54 & 0,79 & 0,13 & 6,20 & 4,32 & 4,94 \\
\hline 5 & 85,81 & 0,56 & 0,04 & 1,56 & 0,40 & 0,02 & 6,11 & 3,81 & 4,05 \\
\hline 6 & 78,12 & 0,54 & 0,03 & 1,38 & 0,36 & 0,01 & 9,03 & 2,52 & 4,64 \\
\hline \multicolumn{10}{|c|}{ Condutividade Elétrica $1.500 \mu \mathrm{S} \mathrm{cm}^{-1}$} \\
\hline 1 & 93,60 & 1,11 & 0,77 & 3,16 & 1,71 & 1,54 & 5,98 & 7,17 & 3,48 \\
\hline 2 & 82,77 & 1,09 & 0,59 & 3,19 & 1,36 & 1,23 & 10,52 & 5,98 & 4,49 \\
\hline 3 & 80,85 & 1,06 & 0,38 & 2,59 & 1,28 & 1,09 & 7,90 & 6,59 & 4,37 \\
\hline 4 & 84,71 & 0,99 & 0,19 & 2,09 & 1,08 & 0,89 & 5,30 & 6,45 & 3,76 \\
\hline 5 & 91,28 & 1,17 & 0,18 & 2,37 & 1,03 & 0,45 & 5,29 & 5,38 & 4,95 \\
\hline 6 & 85,43 & 0,88 & 0,12 & 2,18 & 0,72 & 0,27 & 6,01 & 4,38 & 2,86 \\
\hline Média & 83,65 & 0,84 & 0,23 & 1,96 & 0,88 & 0,52 & 6,69 & 4,65 & 4,32 \\
\hline
\end{tabular}
a relação de adsorção de sódio (RAS) da solução percolante 
(Neossolo Quartzarênico) a muito lenta (Neossolo Flúvico, Chernossolo Argilúvico e Luvissolo Hipocrômico) (Tabela 1) dificultando a comparação dos resultados experimentais.

Para facilitar a visualização das modificações da $\mathrm{K}_{0}$ com os tratamentos impostos, definiu-se a condutividade hidráulica relativa $\left(\mathrm{K}_{0 \mathrm{R}}\right)$ atribuindo-se $100 \%$ à máxima $\mathrm{K}_{0}$ média de cada solo (Neossolo Quartzarênico $=93,60$, Neossolo Regolítico $=1,48$, Neossolo Flúvico $=0,77$, Luvissolo Crômico $=3,19$, Chernossolo Argilúvico $=1,85$, Luvissolo Hipocrômico $=1,54$, Argissolo Vermelho-Amarelo $=10,52$, Planossolo Háplico $=7,17$ e Argissolo Amarelo $\left.=6,06 \mathrm{~cm} \mathrm{~h}^{-1}\right)\left(\right.$ Tabela 2). Os valores de $\mathrm{K}_{0 \mathrm{R}}$ foram relacionados com a CE e a RAS dos tratamentos impostos, ajustando-se superfícies de resposta (Tabela 3 ). $\mathrm{A} \mathrm{K}_{0 \mathrm{R}}$ tem sido

\footnotetext{
" Muito rápida (superior a $25 \mathrm{~cm} \mathrm{~h}^{-1}$ ); Rápida (de 12,5 a $25 \mathrm{~cm} \mathrm{~h}^{-1}$ ); Moderadamente rápida (de 6,25 a 12,5 $\mathrm{cm} \mathrm{h}^{-1}$ ); Moderada (de 2,0 a 6,25 $\mathrm{cm} \mathrm{h}^{-1}$ ); Moderadamente lenta (de 0,5 a 2,0 $\mathrm{cm} \mathrm{h}^{-1}$ ); Lenta (de 0,125 a $0,5 \mathrm{~cm} \mathrm{~h}^{-1}$ ) e Muito lenta (inferior a $0,125 \mathrm{~cm} \mathrm{~h}^{-1}$ )
}

amplamente estudada na tentativa de caracterização de solos sódicos (Rowell et al., 1969; Cass \& Sumner, 1982a,b; Irurtia \& Peinemann, 1986; Yousaf et al., 1987; Melo et al., 1988).

Os valores da Kor do Neossolo Quartzarênico, do Argissolo Vermelho-Amarelo e do Argissolo Amarelo, não se ajustaram a nenhum dos modelos de superfície de resposta testados. Para esses solos, os valores médios de Kor foram de 89,4, 63,9 e 71,3\% (Tabela 3), correspondendo à $\mathrm{K}_{0}$ de $83,65,6,69$ e 4,32 $\mathrm{cm} \mathrm{h}^{-1}$, respectivamente (Tabela 1). A ausência de resposta pode ser atribuída ao caráter extremamente arenoso do Neossolo Quartzarênico, à elevada proporção de cascalho do Argissolo Vermelho-Amarelo e ao caráter latossólico e microestruturado do Argissolo Amarelo. A baixa dispersão inicial de argilas no Argissolo Vermelho-Amarelo e no Argissolo Amarelo, também pode ter motivado esse comportamento. Ressalta-se que, nesses dois solos, os tratamentos impostos não provocaram o

Tabela 2. Condutividade hidráulica relativa $\left(\mathrm{K}_{\mathrm{OR}}\right)^{1}$ em meio saturado das amostras de solo, considerando-se a condutividade elétrica (CE) e a relação de adsorção de sódio (RAS) da solução percolante

\begin{tabular}{|c|c|c|c|c|c|c|c|c|c|}
\hline $\begin{array}{c}\text { Nível } \\
\text { da RAS }\end{array}$ & $\begin{array}{c}\text { Neossolo } \\
\text { Quartzarênico }\end{array}$ & $\begin{array}{l}\text { Neossolo } \\
\text { Regolítico }\end{array}$ & $\begin{array}{l}\text { Neossolo } \\
\text { Flúvico }\end{array}$ & $\begin{array}{l}\text { Luvissolo } \\
\text { Crômico }\end{array}$ & $\begin{array}{c}\text { Chernossolo } \\
\text { Argilúvico }\end{array}$ & $\begin{array}{l}\text { Luvissolo } \\
\text { Hipocrômico }\end{array}$ & $\begin{array}{c}\text { Argissolo } \\
\text { Vermelho- } \\
\text { Amarelo }\end{array}$ & $\begin{array}{l}\text { Planossolo } \\
\text { Háplico }\end{array}$ & $\begin{array}{c}\text { Argissolo } \\
\text { Amarelo }\end{array}$ \\
\hline & \multicolumn{9}{|c|}{$\%$} \\
\hline 1 & 77,54 & 100,00 & 54,06 & 67,46 & 78,17 & 51,13 & 68,10 & 89,08 & 84,32 \\
\hline 2 & 89,35 & 46,73 & 19,61 & 77,64 & 46,64 & 18,37 & 46,81 & 68,28 & 62,00 \\
\hline 3 & 78,31 & 54,72 & 10,87 & 45,63 & 16,18 & 8,53 & 64,09 & 58,82 & 71,87 \\
\hline 5 & 90,09 & 22,55 & 2,95 & 11,00 & 4,89 & 0,23 & 68,84 & 15,95 & 73,90 \\
\hline 6 & 80,80 & 26,31 & 1,76 & 8,34 & 2,81 & 0,02 & 55,30 & 17,11 & 64,04 \\
\hline \multicolumn{10}{|c|}{ Condutividade Elétrica $500 \mu \mathrm{S} \mathrm{cm}^{-1}$} \\
\hline 1 & 95,55 & 96,89 & 82,44 & 70,09 & 100,00 & 86,05 & 58,10 & 86,86 & 76,71 \\
\hline 2 & 85,01 & 58,07 & 42,51 & 83,37 & 72,70 & 58,07 & 51,54 & 75,94 & 100,00 \\
\hline 3 & 95,90 & 52,97 & 15,98 & 84,17 & 57,80 & 21,83 & 69,29 & 63,90 & 61,00 \\
\hline 1 & 100,00 & 75,15 & 100,00 & 98,90 & 92,72 & 100,00 & 56,80 & 100,00 & 57,49 \\
\hline 2 & 88,43 & 73,57 & 76,12 & 100,00 & 73,69 & 80,00 & 100,00 & 83,47 & 74,08 \\
\hline 3 & 86,38 & 72,14 & 48,80 & 81,14 & 69,04 & 70,65 & 81,42 & 91,89 & 72,16 \\
\hline 4 & 90,50 & 67,37 & 25,13 & 65,57 & 58,20 & 57,61 & 50,39 & 89,93 & 62,11 \\
\hline 5 & 97,52 & 79,47 & 23,60 & 74,29 & 55,59 & 29,11 & 50,26 & 75,10 & 81,75 \\
\hline 6 & 91,27 & 59,68 & 15,80 & 68,14 & 38,86 & 17,67 & 57,14 & 61,04 & 47,15 \\
\hline
\end{tabular}

Tabela 3. Superfícies de resposta relacionando-se a condutividade hidráulica relativa em meio saturado $\left(\mathrm{K}_{0 \mathrm{R}}\right)$ com a condutividade elétrica (CE) em $\mu \mathrm{S} \mathrm{cm}^{-1}$, e a relação de adsorção de sódio (RAS) em $\left(\mathrm{mmol}_{\mathrm{c}} \mathrm{L}^{-1}\right)^{1 / 2}$ das soluções aplicadas

Neossolo Quartzarênico $\mathrm{K}_{0 \mathrm{R}}=\overline{\mathrm{K}}_{\mathrm{OR}}=89,4$

Neossolo Regolítico $\quad \mathrm{K}_{0 \mathrm{R}}=73,2+0,01870 * * \mathrm{CE}-3,505 * * \mathrm{RAS}+0,06863 *(\mathrm{RAS})^{2}$

Neossolo Flúvico $\quad \mathrm{K}_{0 \mathrm{R}}=50,3+0,03703 * * \mathrm{CE}-5,767 * * \mathrm{RAS}+0,1535^{* *}(\mathrm{RAS})^{2}-0,001075^{\circ}$ CE RAS

Luvissolo Crômico $\quad \mathrm{K}_{0 \mathrm{R}}=57,3+0,08494 * \mathrm{CE}-0,00003894 * \mathrm{CE}^{2}-2,619 *$ RAS $+0,0009054^{\circ} \mathrm{CE}$ RAS

Chernossolo Argilúvico $\mathrm{K}_{0 \mathrm{R}}=56,8+0,1042 * * \mathrm{CE}-0,00005155^{* *}(\mathrm{CE})^{2}-5,579 * * \mathrm{RAS}+0,08933 * *(\mathrm{RAS})^{2}+0,0008968 * \mathrm{CE} \mathrm{RAS}$

Luvissolo Hipocrômico $\mathrm{K}_{0 \mathrm{R}}=53,8+0,03354 * \mathrm{CE}-5,363 * * \mathrm{RAS}+0,09987 *(\mathrm{RAS})^{2}$

Argissolo

Vermelho-Amarelo $\mathrm{K}_{0 \mathrm{R}}=\overline{\mathrm{K}}_{\mathrm{OR}}=63,9$

Planossolo Háplico $\quad \mathrm{K}_{0 \mathrm{R}}=83,1+0,01055 \mathrm{CE}-4,873 * *$ RAS $+0,001962 *$ CE RAS

0,716

0,968

0,869

0,961

0,919

Argissolo Amarelo $\quad \mathrm{K}_{0 \mathrm{R}}=\overline{\mathrm{K}}_{\mathrm{OR}}=71,3$ 
aparecimento de turbidez nos efluentes como nos outros solos, o que leva à suposição de que os colóides se mantiveram floculados.

A Figura 1 apresenta cortes nas superfícies de resposta ajustadas (Tabela 3), correspondentes aos valores de $\mathrm{CE}$ impostos para os seis solos em que houve diferenciação entre os tratamentos.

Os maiores decréscimos na $\mathrm{K}_{0}$ ocorreram para o Luvissolo Hipocrômico nas soluções mais diluídas $\left(175 \mu \mathrm{S} \mathrm{cm}^{-1}\right)$ que passaram da classe moderadamente lenta, na RAS zero, para muito lenta, na RAS de 15 a $25\left(\text { mmol }_{\mathrm{c}} \mathrm{L}^{-1}\right)^{1 / 2}$ correspondentes aos níveis 4, 5 e 6, (Tabela 1). Este solo é o mais argiloso dentre aqueles com predomínio de esmectita (Freire, 2001) com elevado grau de dispersão inicial, o que o caracteriza como um solo suscetível aos efeitos do sódio e à baixa concentração salina da solução percolante.

O comportamento evidenciado na Figura 1 é coerente com o encontrado por outros pesquisadores, em que o uso de soluções de baixas concentrações salinas e altos valores de RAS resultou em reduções na $\mathrm{K}_{0}$ (McNeal \& Coleman, 1966; Frenkel et al., 1978; Gupta et al., 1984; Minhas \& Sharma, 1986; Costa et al., 1991). Esses decréscimos podem ser atribuídos também à mineralogia dos solos. McNeal \& Coleman (1966) observaram uma diminuição considerável na condutividade hidráulica para solos com predominância de minerais $2: 1$, principalmente esmectita, enquanto um solo caulinítico e com elevados teores de óxidos de ferro apresentou-se estável e não sofreu os efeitos da composição da solução percolante.

A K $\mathrm{OR}_{\mathrm{R}}$ do Neossolo Flúvico, do Luvissolo Crômico, do Chernossolo Argilúvico e do Planossolo Háplico, também decresceu com a elevação da RAS e com a diminuição da concentração salina das soluções percolantes (Tabela 2, Figura 1). O Neossolo Regolítico, apesar da textura arenosa, apresentou resposta aos tratamentos impostos, o que poderia ser atribuído ao seu caráter fragipânico, induzindo ao adensamento das partículas na montagem das colunas. Tal comportamento pode ser comprovado pelo reduzido valor da $\mathrm{K}_{0}$ média (Tabela 1).

As curvas de $\mathrm{K}_{0 R}$ em função da RAS, quando se fixa à CE da solução de trabalho (Figura 1), não se apresentam paralelas nos solos em que a interação CE x RAS foi significativa (Tabela 3). Exceto no Neossolo Regolítico e no Luvissolo Hipocrômico, nos quatro solos restantes as curvas correspondentes à maior concentração eletrolítica $\left(1.500 \mu \mathrm{S} \mathrm{cm}^{-1}\right)$ foram as que mostraram menor diminuição da $\mathrm{K}_{\mathrm{OR}}$ com o incremento da RAS.

A curva correspondente a $175 \mu \mathrm{S} \mathrm{cm}^{-1}$ do Neossolo Flúvico apresentou valores nulos de $\mathrm{K}_{\mathrm{OR}}$ a partir da RAS $16,8\left(\text { mmol }_{\mathrm{c}} \mathrm{L}^{-1}\right)^{1 / 2}$, valor-limite para o modelo ajustado. Assim, para qualquer RAS $\geq 16,8\left(\mathrm{mmol}_{\mathrm{c}} \mathrm{L}^{-1}\right)^{1 / 2}$ nesta $\mathrm{CE}$, a $\mathrm{K}_{0 \mathrm{R}}$ seria nula (Tabela 3, Figura 1B) o mesmo ocorreu com o Chernossolo Argilúvico (Figura 1D) e o Luvissolo Hipocrômico (Figura 1E), em que a $\mathrm{K}_{\text {or }}$ se anulou para os valores de RAS $\geq 20,4$ e $15,7\left(\text { mmolc }^{-1}\right)^{1 / 2}$ respectivamente, para uma $\mathrm{CE}$ de $175 \mu \mathrm{S} \mathrm{cm} \mathrm{cm}^{-1}$. O Luvissolo Hipocrômico apresentou, ainda, valores nulos de $\mathrm{K}_{\mathrm{OR}}$ para uma RAS a partir de 23,0 (mmolc $\left.\mathrm{L}^{-1}\right)^{1 / 2}$ sob uma CE de $500 \mu \mathrm{S} \mathrm{cm}^{-1}$ (Figura 1E).
A. Neossolo Regolítico

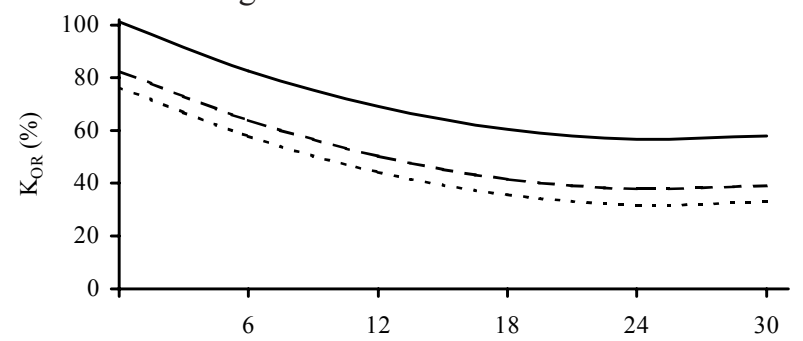

B. Neossolo Flúvico

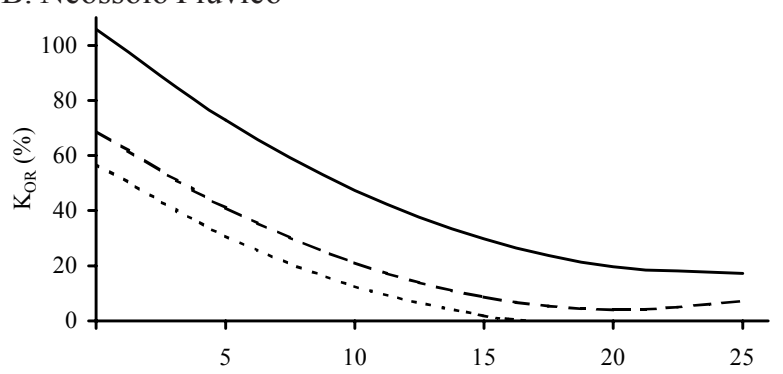

C. Luvissolo Crômico

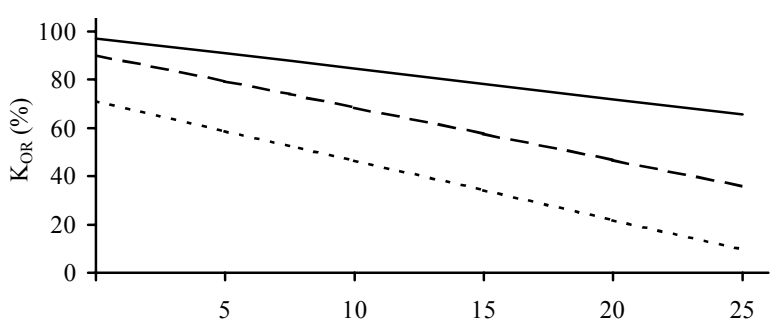

D. Chermossolo Argilúvico

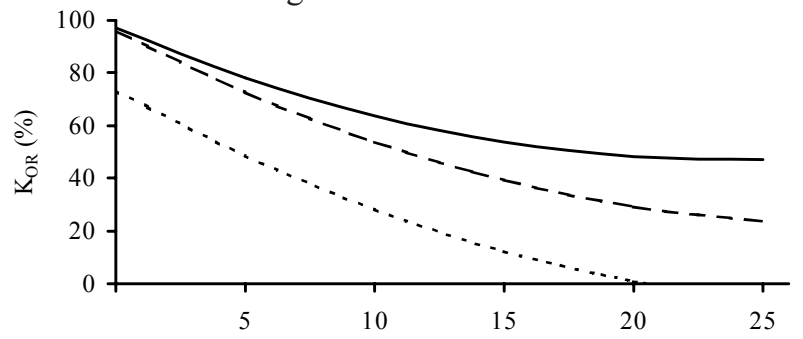

E. Luvissolo Hipocrômico

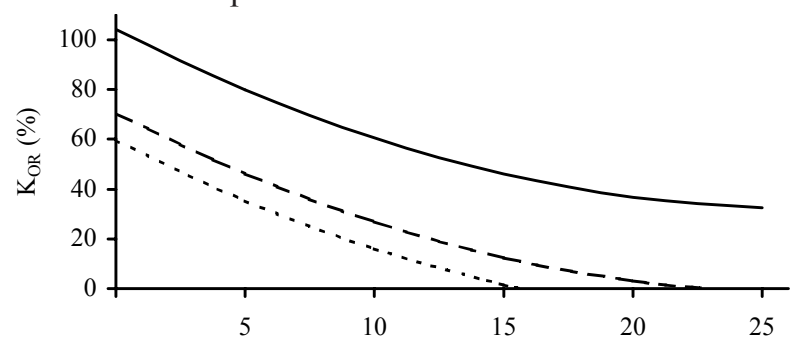

F. Planossolo Háplico

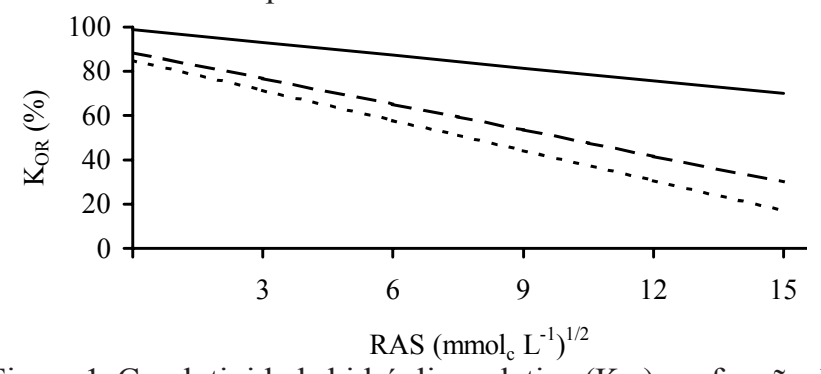

Figura 1. Condutividade hidráulica relativa $\left(\mathrm{K}_{0 \mathrm{R}}\right)$ em função da relação de adsorção de sódio (RAS) em amostras dos solos estudados para condutividades elétricas de 1.500 (...), 500 (---) e $175(-) \mu \mathrm{S} \mathrm{cm}^{-1}$, respectivamente 
Soluções mais concentradas $\left(1.500 \mu \mathrm{S} \mathrm{cm}^{-1}\right)$ possibilitaram a manutenção de maiores valores de $\mathrm{K}_{0 \mathrm{r}}$. Poderia, então, a água de irrigação classificada como $\mathrm{C}_{3}\left(750-2.250 \mu \mathrm{S} \mathrm{cm}^{-1}\right)$ ser utilizada sob certas condições em que outra água $C_{1}\left(100-250 \mu \mathrm{S} \mathrm{cm}^{-1}\right)$ promovesse limitação na $\mathrm{K}_{0 \mathrm{R}}$ ? É uma questão a ser analisada sob diversos aspectos, pois esta mesma solução, mais concentrada, pode estar conduzindo a um processo de salinização e/ ou sodificação mais acentuado que a $\mathrm{C}_{1}$, pois contém mais sais. É preciso que haja uma preocupação constante com a natureza das relações entre os componentes solúveis e trocáveis nos solos, para evitar a evolução dos processos de salinização e/ou sodificação.

No intuito de se estabelecer um valor de PST crítico na definição de solos sódicos determinaram-se, inicialmente, correlações entre $\mathrm{K}_{0}$ e PST. Quando consideradas as 162 médias correspondentes aos tratamentos impostos $(9$ solos x 3 CE x 6 RAS) o coeficiente de correlação linear simples foi extremamente baixo, indicando a necessidade de se selecionar os dados experimentais. Utilizando-se como critério de seleção a condutividade elétrica da solução, os valores tampouco foram satisfatórios; já no agrupamento por solo, apenas quatro apresentaram elevados coeficientes de correlação linear simples entre $\mathrm{K}_{0}$ e PST. Esta constatação levou à seleção dos dados experimentais considerando-se, individualmente, cada solo e cada CE (Tabela 4).

Tabela 4. Coeficientes de correlação linear simples relacionando a condutividade hidráulica em meio saturado e a percentagem de sódio trocável, considerando-se o solo e a condutividade elétrica (seis médias)

\begin{tabular}{llll}
\hline \multirow{2}{*}{ Solo } & \multicolumn{3}{c}{ Condutividade Elétrica $\left(\mu \mathrm{S} \mathrm{cm}^{-1}\right)$} \\
\cline { 2 - 4 } & \multicolumn{1}{c}{175} & 500 & 1.500 \\
\hline Neossolo Quartzarênico & 0,319 & $-0,477$ & $-0,302$ \\
Neossolo Regolítico & $-0,949^{* *}$ & $-0,976^{* *}$ & $-0,429$ \\
Neossolo Flúvico & $-0,857^{*}$ & $-0,920^{* *}$ & $-0,978^{* *}$ \\
Luvissolo Crômico & $-0,945^{* *}$ & $-0,770^{*}$ & $-0,887^{* *}$ \\
Chernossolo Argilúvico & $-0,927^{* *}$ & $-0,991^{* *}$ & $-0,971^{* *}$ \\
Luvissolo Hipocrômico & $-0,862^{*}$ & $-0,949^{* *}$ & $-0,980^{* *}$ \\
Argissolo Vermelho-Amarelo & $-0,059$ & 0,517 & $-0,372$ \\
Planossolo Háplico & $-0,953^{* *}$ & $-0,965^{* *}$ & $-0,825^{*}$ \\
Argissolo Amarelo & $-0,576$ & $-0,278$ & $-0,080$ \\
\hline${ }^{*} \mathrm{e}^{* *}$ Significativos aos niveis de 5e $1 \%$, respectivamente, pelo teste t &
\end{tabular}

Os resultados apresentados na Tabela 4 evidenciam correlação não-significativa para as amostras do Neossolo Quartzarênico, do Argissolo Vermelho-Amarelo e do Argissolo Amarelo, precisamente os três materiais em que não foi possível ajustar-se superfícies de resposta para $\mathrm{K}_{0 \mathrm{R}} \mathrm{e}$, por extensão, de $\mathrm{K}_{0}$ (Tabela 3), quando relacionada com a CE e a RAS. Os seis solos restantes mostraram correlações significativas e negativas, indicando relação inversa entre $\mathrm{K}_{0}$ e PST. Deste grupo de solos, o único valor de $r$ não-significativo foi registrado para o Neossolo Regolítico, quando tratado com a solução de CE de $1.500 \mu \mathrm{S} \mathrm{cm}^{-1}$. Os resultados indicam que, para uma CE fixa, a $\mathrm{K}_{0}$ correlaciona-se com a PST naqueles solos que apresentam resposta às variações da RAS da água de irrigação.

Tradicionalmente, considera-se que uma PST maior que 15\% afeta as propriedades estruturais e hidráulicas do solo (Richards, 1954). No entanto, pesquisas recentes têm demonstrado que o valor crítico e o conceito de limite crítico precisam ser reconsiderados, pois a degradação das propriedades físicas do solo pode ocorrer a valores de PST mais baixos em soluções diluídas (Crescimanno et al., 1995).

Qual seria, então, o limite de PST a ser adotado para todos os solos? Se for considerado que a degradação das propriedades físicas se inicia a uma $\mathrm{K}_{0}$ menor que $0,1 \mathrm{~cm} \mathrm{~h}^{-1}$ (Richards, 1954; McIntyre, 1979) apenas o Neossolo Flúvico, o Chernossolo Argilúvico e o Luvissolo Hipocrômico estariam sujeitos a uma PST crítica (Tabela 1); contudo, encontram-se relatos na literatura de que uma redução de 10,15 ou $25 \%$ na Kor caracteriza a PSTlimite (Rowell et al., 1969; Cass \& Sumner, 1982b; Irurtia \& Peinemann, 1986; Yousaf et al., 1987; Melo et al., 1988). Todavia, para definição da $\mathrm{K}_{0}$-limite, têm sido propostos modelos que permitam indicar o ponto em que se inicia a degradação da agregação do solo (Cass \& Sumner, 1982a) porém nem mesmo para esta degradação há um limite crítico definido, devendo ser considerado o que ocorre em cada solo.

Buscando-se encontrar uma PST-limite para classificar os solos sódicos do Estado de Pernambuco, selecionaram-se os seis materiais que apresentaram resposta aos tratamentos. Como nem todos atingiram o valor de PST de 15, fixaram-se os valores de 5 e $10 \%$, calculando-se as $\mathrm{K}_{0}$ associadas (Tabela 5). Para isto, determinaram-se os valores de RAS que correspondem às PST indicadas; esses valores foram usados para se calcular as respectivas $\mathrm{K}_{\mathrm{OR}}$ (Tabela 3). Os valores foram transformados para $\mathrm{K}_{0}$, multiplicando-os pela $\mathrm{K}_{0}$ média máxima de cada solo.

Tabela 5. Condutividade hidráulica em meio saturado $\left(\mathrm{cm} \mathrm{h}^{-1}\right)$ determinada para percentagens de sódio trocável de 5 e $10 \%$, considerando-se a condutividade elétrica da solução percolante

\begin{tabular}{ccc}
\multirow{3}{*}{ Solo } & \multicolumn{3}{c}{ Condutividade elétrica $\left(\mu \mathrm{S} \mathrm{cm}^{-1}\right)$} \\
\cline { 2 - 4 } & \multicolumn{3}{c}{500} & 1.500 \\
\cline { 2 - 3 } & \multicolumn{3}{c}{$\mathrm{K}_{0}\left(\mathrm{~cm} \mathrm{~h}^{-1}\right)$} \\
\hline
\end{tabular}

\begin{tabular}{lccc}
\hline \multicolumn{4}{c}{ Percentagem de Sódio Trocável de 5\% } \\
Neossolo Regolítico & 1,58 & 1,56 & 1,59 \\
Neossolo Flúvico & 0,15 & 0,23 & 0,50 \\
Luvissolo Crômico & 1,60 & 2,32 & 2,83 \\
Chernossolo Argilúvico & 0,85 & 1,32 & 1,49 \\
Luvissolo Hipocrômico & 0,56 & 0,74 & 3,17 \\
Planossolo Háplico & 4,11 & 5,46 & 6,54 \\
\hline \multicolumn{4}{c}{ Percentagem de Sódio Trocável de 10\% } \\
Neossolo Regolítico & 1,86 & 2,07 & 2,15 \\
Neossolo Flúvico & 0,00 & 0,04 & 0,20 \\
Luvissolo Crômico & 0,75 & 1,58 & 2,41 \\
Chernossolo Argilúvico & 0,40 & 0,90 & 1,16 \\
Luvissolo Hipocrômico & 0,23 & 0,41 & 0,97 \\
Planossolo Háplico & 0,19 & 1,29 & 5,41 \\
\hline I Listados somente os solos que apresentaram resposta aos tratamentos
\end{tabular}

Considerando-se outros critérios enunciados, como a redução da KOR (Rowell et al., 1969; Cass \& Sumner, 1982b; Irurtia \& Peinemann, 1986; Yousaf et al., 1987; Melo et al., 1988) determinaram-se os valores de PST, que levaram a reduções da $\mathrm{K}_{\mathrm{OR}}$ média de 25 e $50 \%$, respectivamente (Tabela 6). Para isto, calcularam-se os valores da RAS que permitiram atingir 75 e $50 \%$ de $\mathrm{K}_{\mathrm{OR}}$ (Tabela 3); posteriormente, a utilização das superfícies de resposta relacionando PST com CE e RAS das soluções aplicadas, permitiu o cálculo das PST associadas com as reduções apontadas. 
Tabela 6. Percentagem de sódio trocável que provoca redução de 25 e $50 \%$ da $\mathrm{K}_{0 \mathrm{R}}$, considerando-se a condutividade elétrica da solução percolante ${ }^{1}$

\begin{tabular}{|c|c|c|c|}
\hline \multirow{2}{*}{ Solos } & \multicolumn{3}{|c|}{ Condutividade Elétrica $\left(\mu \mathrm{S} \mathrm{cm}^{-1}\right)$} \\
\hline & 175 & 500 & 1.500 \\
\hline \multicolumn{4}{|c|}{ Redução de $25 \%$ da $\mathrm{K}_{0 \mathrm{R}}$} \\
\hline Neossolo Regolítico & 3,29 & 4,06 & 3,67 \\
\hline Neossolo Flúvico & & & 4,11 \\
\hline Luvissolo Crômico & & 4,42 & 10,23 \\
\hline Chernossolo Argilúvico & & 4,29 & 6,44 \\
\hline Luvissolo Hipocrômico & & & 7,25 \\
\hline Planossolo Háplico & 2,77 & 4,81 & 7,19 \\
\hline \multicolumn{4}{|c|}{ Redução de $50 \%$ da $\mathrm{K}_{0 \mathrm{R}}$} \\
\hline Neossolo Regolítico & 5,73 & 7,66 & 9,68 \\
\hline Neossolo Flúvico & 1,58 & 2,82 & 6,54 \\
\hline Luvissolo Crômico & 5,01 & 9,90 & 16,82 \\
\hline Chernossolo Argilúvico & 4,22 & 9,72 & 15,54 \\
\hline Luvissolo Hipocrômico & 2,16 & 4,62 & 13,62 \\
\hline Planossolo Háplico & 5,72 & 8,08 & 12,52 \\
\hline
\end{tabular}

Listados somente os solos que apresentaram resposta aos tratamentos

Observa-se, pela Tabela 6, a grande variabilidade dos valores de PST associados às diferentes CE de trabalho. Assim, levando-se em conta uma redução de $25 \%$ na $\mathrm{K}_{\mathrm{OR}}$, nenhum solo alcançaria a PST de 15, nem mesmo com a água de 1.500 $\mu \mathrm{S} \mathrm{cm}^{-1}$ de CE; apenas o Luvissolo Crômico e o Chernossolo Argilúvico chegariam a esse valor para a CE de $1.500 \mu \mathrm{S} \mathrm{cm}^{-1}$, mas com uma redução de $50 \%$ na $\mathrm{K}_{\mathrm{OR}}$. Tal fato corresponderia a uma $\mathrm{K}_{0}$ média de 0,98 e 0,44 $\mathrm{cm} \mathrm{h}^{-1}$, para o Luvissolo Crômico e o Chernossolo Argilúvico, respectivamente. Fica claro que a PST para reduções de 25 e $50 \%$ na $\mathrm{K}_{\mathrm{OR}}$, se altera, conforme o solo e a CE da água utilizada na irrigação, não sendo possível usar um único valor para qualquer situação.

Por outro lado, a discrepância nos valores de $\mathrm{K}_{0}$ dos solos utilizados (Tabela 1), torna desaconselhável a utilização da $\mathrm{K}_{\mathrm{OR}}$ que agruparia, no mesmo percentual de redução de $\mathrm{K}_{0}$, solos com acentuadas diferenças nos seus valores médios absolutos $\left(83,65 \mathrm{~cm} \mathrm{~h}^{-1}\right.$ para o Neossolo Quartzarênico e $0,23 \mathrm{~cm} \mathrm{~h}^{-1}$ para o Neossolo Flúvico, respectivamente, Tabela 1).

Os dados apresentados permitem evidenciar-se que os solos podem responder de forma diferenciada à proporção de sódio no complexo de troca catiônica. Dos nove materiais estudados, três não sofreram modificações na $\mathrm{K}_{\mathrm{OR}} \mathrm{e}$, por extensão, na $\mathrm{K}_{0}$, (Tabela 3), pelos tratamentos impostos, seja pela textura extremamente arenosa, seja pela mineralogia ou pela presença de óxidos de ferro, que favoreceu a infiltração e a movimentação de água mas, ainda nesses casos, é necessário destacar que a presença de proporções elevadas de sódio levaria a uma deterioração dos agregados do solo pela elevação da dispersividade dos minerais da fração argila.

Onde houve resposta aos tratamentos, não foi possível se fixar um único valor de PST que deveria estar, necessariamente, associado à CE da água; assim, cada solo deveria ser analisado individualmente, considerando-se a água disponível para uso em irrigação. O critério a ser utilizado deveria contemplar um valor absoluto de $\mathrm{K}_{0}$ considerado crítico, associado também a trabalhos que objetivem quantificar o crescimento adequado de raízes nas condições impostas. A utilização de valores relativos de $\mathrm{K}_{0}$ somente seria aconselhável na comparação de solos que apresentem composição mineralógica, quali e quantitativa semelhante.

\section{CONCLUSÕES}

1. O incremento da relação de adsorção de sódio da água de irrigação resultou na diminuição da condutividade hidráulica $\left(\mathrm{K}_{0}\right)$, das amostras dos solos estudados.

2. Na maioria dos solos, as correlações entre $\mathrm{K}_{0}$ e a percentagem de sódio trocável, indicaram uma relação inversa entre essas variáveis.

3. Os solos responderam de forma diferenciada à salinidade da solução e à proporção de sódio no complexo de troca catiônica.

4. Independentemente de não se ter atingido a PST de 15\%, em alguns solos observou-se a impossibilidade de se utilizar um único valor de PST na fixação de um limite responsável pela redução da condutividade hidráulica.

5. Cada solo precisa ser analisado individualmente, considerando-se a água disponível para uso em irrigação.

\section{AGRADECIMENTOS}

À Área de Solos do Departamento de Agronomia da Universidade Federal Rural de Pernambuco, pelo apoio nas atividades de coleta e preparo das amostras de solo, bem como na realização de algumas análises.

\section{LITERATURA CITADA}

Cass, A.; Sumner, M.E. Soil pore structural stability and irrigation water quality: I. Empirical sodium stability model. Soil Science Society of America Journal, Madison, v.46, p.503-506, 1982a.

Cass, A.; Sumner, M.E. Soil pore structural stability and irrigation water quality: II. Sodium stability data. Soil Science Society of America Journal, Madison, v.46, p.507-512, 1982 b.

Costa, J.L.; Prunty, L.; Montgomery, B.R.; Richardson, J.L.; Alessi, R.S. Water quality effects on soils and alfalfa: II. Soil physical and chemical properties. Soil Science Society of America Journal, Madison, v.55, p.203-209, 1991.

Crescimanno, G.; Iovino, M.; Provenzano, G. Influence of salinity and sodicity on soil structural and hydraulic characteristics. Soil Science Society of America Journal, Madison, v.59, p.1701-1708, 1995.

Ferreira, P.A. Drenagem de terras agrícolas. Viçosa: Universidade Federal de Viçosa, 1999. 187p.

Fireman, M.; Wadleigh, C.H. A statistical study of the relation between $\mathrm{pH}$ and the exchangeable-sodium-percentage of western soils. Soil Science, Baltimore, v.71, p.273-285, 1951.

Freire, M.B.G. dos S. Saturação por sódio e qualidade da água de irrigação na degradação de propriedades físicas de solos do Estado de Pernambuco. Viçosa: Universidade Federal de Viçosa, 2001.66 p. Tese Doutorado 
Frenkel, H.; Goertzen, J.O.; Rhoades, J.D. Effects of clay type and content, exchangeable sodium percentage, and electrolyte concentration on clay dispersion and soil hydraulic conductivity. Soil Science Society of America Journal, Madison, v.42, p.32-39, 1978.

Gupta, R.K.; Bhumbla, D.K.; Abrol, I.P. Effect of sodicity, pH, organic matter, and calcium carbonate on the dispersion behavior of soils. Soil Science, Baltimore, v.137, p.245-251, 1984.

Irurtia, B.; Peinemann, N. Efecto de la relación de adsorción de sodio y la concentración de sales sobre la conductividad hidráulica de diferentes suelos. Ciencia del Suelo, Buenos Aires, v.2, p.165-177, 1986.

McIntyre, D.S. Exchangeable sodium, subplasticity and hydraulic conductivity of some Australian soils. Australian Journal of Soil Research, Collingwood, v.17, p.115-120, 1979.

McNeal, B.L.; Coleman, N.T. Effect of solution composition on soil hydraulic conductivity. Soil Science Society of America Proceedings, Madison, v.30, p.308-312, 1966.

Melo, F.B.; Coelho, M.A.; Ferreyra, H.F.F. Efeitos do gesso e da concentração salina da água na condutibilidade hidráulica do solo. Revista Brasileira de Ciência do Solo, Campinas, v.12,p.89-92, 1988.

Minhas, P.S.; Sharma, D.R. Hydraulic conductivity and clay dispersion as affected by application sequence of saline and simulated rain water. Irrigation Science, Berlin, v.63, p.159-167, 1986.
Northcote, K.H.; Skene, J.K.M. Australian soils with saline and sodic properties. Melbourne: CSIRO, 1972. 62p. Soil Publication 27

Ribeiro, M.R.; Jacomine, P.K.T.; Ferreira, M.G.V.X.; Rodrigues, J.J.V.; Lima, J.F.W.F. Caracterização e classificação de solos de referência do Estado de Pernambuco. Recife: Universidade Federal Rural de Pernambuco, 1999. Relatório do Projeto Integrado CNPq/FACEPE, Processo 523205/96-1

Richards, L.A. Diagnosis and improvement of saline and alkali soils. Washington: US Department of Agriculture, 1954. 160p. USDA Agricultural Handbook, 60

Rowell, D.L.; Payne, D.; Ahmad, N. The effect of the concentration and movement of solutions on the swelling, dispersion, and movement of clay in saline and alkali soils. Journal of Soil Science, Oxford, v.20, p.176-188, 1969.

Sumner, M.E. Sodic soils: New perspectives. In: Naidu, R.; Sumner, M.E.; Rengasamy, P. (eds.). Australian sodic soils. Distribution, properties and management. Melbourne: CSIRO, 1995. p.1-34.

Yousaf, M.; Ali, O.M.; Rhoades, J.D. Clay dispersion and hydraulic conductivity of some salt-affected arid land soils. Soil Science Society of America Journal, Madison, v.51, p.905-907, 1987. 